\title{
Conservation Priorities for Indian Goat Breeds Based on Microsatellite and Analytical Data
}

\author{
Rajkumar Sah ${ }^{1,2 *}$ and S.P. Dixit ${ }^{3}$ \\ ${ }^{1}$ National Dairy Research Institute, Karnal, INDIA \\ ${ }^{2}$ V.K.S. College of Agriculture, Dumraon (BAU, Sabour), Buxar, Bihar, INDIA \\ ${ }^{3}$ National Bureau of Animal Genetics Resources, Karnal, INDIA \\ *Corresponding author: R Sah; E-mail:drrkvet@yahoo.com
}

Received: 22 April, 2020

Revised: 19 May, 2020

Accepted: 24 May, 2020

\begin{abstract}
The demographic and microsatellite data on 25 markers along with non genetic information such as distribution, adaptation and utility pertaining to 24 Indian goat breeds were used to assess their conservation priorities. The effective population size $(\mathrm{Ne})$ of Gohilwadi, Jharkhand Black and Sangamneri was greater than 200 and that of Black Bengal, Kutchi, Mehsana, Sirohi, Malabari and Zalawadi ranged from 100 to 200 but it was below 100 for rest (60\%) of the breeds with Ganjam having the least value of 17.5 based on microsatellite data. All goat breeds whose effective population size is greater than 100 based on markers did have population size between 0.1 and 0.2 million except in few cases. The Ne based on microsatellite and demographic data revealed almost same order of ranking of goat populations. It was also revealed that Attappady and Kutchi were at highest risk of extinction probability $(0.63)$ and more than half of the Indian goat breeds were having less than $50 \%$ extinction probability. Therefore, Attappady and Kutchi should be given top priority for conservation.
\end{abstract}

Keywords: Goat breeds, Census data, Microsatellite, Extinction probability, Conservation priority

There are 34 well recognised and registered goat breeds in India (http://www.nbagr.res.in/reggoat.html) which are widely distributed across all agro-ecological zones of the country and reared mainly by small and marginal farmers. Goats contribute significantly to rural economy as they can sustain on trivial input resources under harsh environmental conditions. They have high prolificacy coupled with small generation interval. The Indian goat population of 135.17 million (Livestock Census, Govt of India, 2012) constituted $17.93 \%$ of the world goat population (868.00 million, FAO statistics, 2009) and $22.63 \%$ of Asian goat population (597.15 million). The goat population of India increased from 47.2 million in 1951-1952 to 135.17 million in 2012, which showed popularity and usefulness of goat domestication. The goat breeds are mainly defined by their geographical position, morphological characteristics and production performance (Dixit et al., 2012). Genetic diversity and relationship among these goats were analyzed based on microsatellite markers (Dixit et al., 2012) and it was concluded that there were three major genetic groups according to their physio-geographical origin. It was also revealed that $83.5 \%$ of the genetic variability in studied breeds was due to differences among individuals within the breed and $16.5 \%$ due to unique allelic differences between the breeds. Within breed genetic variation indicated its robustness to adapt to future climatic and economic needs. However, this approach not only ignores risk status of the breed but also the role of non-genetic factors crucial for their sustainable utilization and conservation. Therefore, a framework incorporating both risk status and non-genetic criteria for prioritizing breeds for their conservation and utilization at the national level is warranted. Hence, the present aim is to set up conservation priority of these goat

How to cite this article: Sah, R. and Dixit, S.P. (2020). Conservation priorities for Indian goat breeds based on microsatellite and analytical data. J. Anim. Res., 10(3): 405-410.

Source of Support: None; Conflict of Interest: None 
genetic resources based on their extinction probability and conservation potential. This type of framework has already been in practice in different livestock species (FAO, 2000; Benewitz et al., 2007; Meuwissen, 2009; Boettcher et al., 2010; Tadano et al., 2013). The risk strategy is based on the numbers of breeding animals (FAO. 2000), inbreeding rate and effective population $(\mathrm{Ne})$ size (Benewitz et al., 2007). Molecular genetic data can contribute to assess the risk status in addition to demographic data on these goats. Risk status or degree of endangerment of a breed is inferred from various criteria: population size, population dynamics, number of breeding males and females, rate of inbreeding, level of indiscriminate crossbreeding, ongoing conservation activities, and risk of natural and human disaster. Comparatively limited number of herds and concentration of the population in a restricted area may also causes a greater risk of extinction (Carson et al., 2009). The presence of controlled or uncontrolled crossbreeding may also affect risk of extinction as genetically in each cross-bred mating, the breed population size is effectively decreased by one half. Ne gives a useful general idea of the dynamics of genetic variability within a given population. A larger $\mathrm{Ne}$ is therefore considered advantageous because of its association with more genetic variation and less inbreeding. $\mathrm{Ne}$ is considered as one of the major criteria for monitoring risk status in livestock populations because it accounts for inbreeding and loss of genetic diversity through random genetic drift (Falconer and Mackay, 1996; Meuwissen, 2009). Leroy et al. (2009) showed that estimates of effective population size varied according to the within-breed genetic structure for different species. With the given background, this study will be helpful in assessing risk for extinction of breed (s) and its conservation value, and thereby deciding conservation priority specific to these goat genetic resources. Moreover, it will also be attempted to study usefulness of STR data in the absence of breed-wise demographic data to decide conservation and prioritization of goats

\section{MATERIALS AND METHODS}

The present research work was conducted at National Bureau of Animal Genetics Resources, Karnal-132001 during 2016-17. The data on 25 STR markers generated for 22 goat breeds had already been published by Dixit et al. (2012). Briefly, 1034 random blood samples (36-48 samples from each breed) were collected from different parts of the country and DNA was isolated using standard protocol. The denatured samples were run on automated DNA sequencer of Applied Biosystems (ABI 3100 Avant). The electropherograms drawn through Gene Scan were used to extract DNA fragment sizing details using Gene Mapper software (version 3.0) (Applied Biosystems, U.S.A.). The breed-wise population data of 24 registered goat breeds was also collected from estimated livestock population breed-wise survey-2013, Department of Animal Husbandry, Government of India. The other relevant information required was based on review of literature viz., breed wise monographs published by National Bureau of Animal genetic Resources, Karnal; Indian J. of animal Sci. vol. 77-83; $19^{\text {th }}$ livestock census, Department of Animal Husbandry, Government of India; Network and NATP project reports of National Bureau of Animal Genetic Resources, Karnal; Scientist opinion and farmers talk and personal experience of the authors with goat farmers.

\section{Risk status of breed}

The extinction risk is mainly based on population size but many other factors also influence the survival of a breed (Ruane, 1999; FAO, 2000). Here, threat status of each breed was assessed based on seven indicators: (1) population size extracted from STR and livestock breedwise survey- 2013, Govt of India, (2) geographical distribution of breed based on survey data of the breed, (3) crossbreeding, (4) conservation program, (5) organized farm, (6) adaptation and (7) uniqueness/special traits of the breed (production/reproduction). We assumed that breeds scoring high value have higher likelihood of being replaced. To calculate extinction probabilities, values between 0 (no effect on threat) and 0.3 (high effect on threat) for threat indicator 1 and between 0 and 0.1 for indicators 2-6 were assigned. Indicator 7 was assigned a value between 0 (high uniqueness) and 0.2 (least uniqueness) based on literature. The values for other indicators were assigned: (1) if population size greater than $3,00,000=$ 0.0 and less that $1,00,000=0.3$, between $1,00,000$ and $2,00,000=0.2$ and between $2,00,000$ and 3,00,000 $=0.1$; similarly based on STR data, if effective population size greater than $80=0.3$, between 80 and $160=0.2,160$ and $240=0.1$ and if less than $240=0.0$ (2) if distributed across states $=0.0$ otherwise $0.1 ;$ (3) if level of indiscriminate crossbreeding is very high $=0.1$ otherwise 0.0 ; (4) if there 
is existing conservation program $=0.0$ otherwise $0.1 ;(5)$ if the breed is maintained at organized farm $=0.0$ otherwise $0.1 ;(6)$ if breed is well adapted based on literature $=0.0$ otherwise 0.1 . All variables were weighted equally except effective population size which was weighted three times of the other variables because the number of animals of a breed was considered a direct and crucial measure for its extinction probability.

\section{Estimation of effective population size (Ne)}

The effective population size (NeLD) was computed from genotypic data using $\mathrm{Ne}$ Estimator 2.01 software based on linkage disequilibrium (Hill, 1981; Waples, 2006). This method was implemented in LDNe program (Waples and Do, 2008), which corrects for biases resulting from the presence of a wide range of sample sizes and rare alleles, and was developed by Waples (2006). The NeLD could be calculated for unlinked loci as $=\mathrm{N}_{\mathrm{eLD}}=1 /\left[3 *\left(r^{2}-1 / \mathrm{S}\right)\right]$ where $r$ is correlation among alleles and $\mathrm{S}$ is sample size (Hill, 1981; Waples, 2006). All alleles with frequencies less than the critical values (PCRIT) of 0.05 were excluded (Waples and Do, 2008). A Jack-knife method was used to construct $95 \%$ confidence intervals of the estimates.

The number of male and female population except those below one year of age was considered for the estimation of $N c$ (effective population size based on census). $N c$ was estimated by using following formula of Wright (1931).

$$
N_{e}=\frac{4 \times N_{m} \times N_{f}}{N_{m}+N_{f}}
$$

Where $N_{m}$ is the no. of male and $N_{f}$ is no. of female.

\section{The extinction probability $(Z)$}

The extinction probability of each breed was computed by summing of all seven variables and the sum was rescaled to a value between 0.1 and 0.9 using the following equation as suggested by Reist-Marti et al. (2003).

$$
Z i=0.8 / 1.2 * \Sigma \mathrm{Zia}+0.1
$$

where $Z i$ is extinction probability of $i^{\text {th }}$ breed and Zia is sum of extinction probability of all the variables $(a=1-7)$.

Journal of Animal Research: v.10 n.3, June 2020

\section{Conservation priorities}

The conservation value of each breed was assessed by considering the all multiple factors as per FAO (2013).

$$
C V_{i}=W_{F 1}\left(F_{1 i}+\mu_{F 1}\right) / \sigma_{F 1}+W_{F 2}\left(F_{2 i}+\mu_{F 2}\right) / \sigma_{F 2}+\ldots,
$$

where, $C V_{i}=$ conservation value of $i^{\text {th }}$ breed; $W_{F 1}=$ weightage given to factor $1 ; F_{I i}=$ value of factor 1 for breed $i$; $\mu_{F 1}=$ average value of factor 1 across all breeds; and $\sigma_{F 1}=$ standard deviation of factor 1 value across all breeds. Higher conservation priority was given to the breed with higher conservation value.

\section{RESULTS AND DISCUSSION}

\section{Effective population size of breeds}

The effective population size and extinction probability of the breeds under study have been presented in table 1 based on demographic and microsatellite data. In most of the cases, the order of ranking of different goat populations on the basis of effective size based on both the data was almost same and hence, revealed effective use of STR data in absence of demographic data. The effective population size of Gohilwadi, Jharkhand Black and Sangamneri was $>200$ and that of Black Bengal, Kutchi, Mehsana, Sirohi, Malabari and Zalawadi ranged from 100 to 200 but it was below 100 for rest $(60 \%)$ of the breeds with Ganjam having the least value of 17.5 based on microsatellite data. This indicated a wide range of genetic variation among Indian goat breeds probably due to mild differentiation across the allele and loci. Some of loci might be highly differentiated because selective forces may be strong enough at such loci to overcome the effect of low effective size (Toro et al., 2006). Therefore, the selective forces acting in these goat populations may also be partially responsible for low effective population size and differentiation among these breeds. The genetic differentiation among these breeds was $16.5 \%$ of the total genetic variation due breed component (Dixit et al. 2012).

Based on demographic data, the highest effective population size $(N c)$ of 8.5 million was estimated in Black Bengal while that of Marwari, Barbari, Jamunapari and Osmanabadi was greater than 0.3 million; and of Attappady, Gohilwadi, Sangamneri, Chegu, Berari and Konkan Kanyal less than 0.1 million. It also showed wide 
variation in population size and distribution of male and female goats in each population. Assuming that NeLD less than 100 and $\mathrm{Nc}$ value close to 0.1 million or less than 0.1 million in these breeds indicated same level of consideration for conservation, $\mathrm{NeLD}$ and $\mathrm{Nc}$ are, in general, in good agreement with each other for most of the breeds under study except Osmanabadi, Jamunapari and Marwari whose Nc value is greater than 0.5 million but Ne less than 100. This disagreement in size of effective population size may be due to non-random sampling of blood samples of these breeds for scoring micro-satellite markers. The higher Fis value (greater than or equal to 0.18 ) also reflected non-random blood sampling of these breeds (Dixit et al., 2012). All goat breeds whose effective population size is greater than 100 based on markers did have population size between 0.1 and 0.2 million. Hence, both the data indicated same level of effective size of these populations except Gohilwadi and Jharkhand Black. Moreover, Cervantes et al. (2011) investigated three different methodologies to compute Ne based on molecular co-ancestry, pedigree data and linkage disequilibrium, and concluded that there was high range for effective population size cross the methodologies and when the priority for conservation was of concern, all methods seemed to be useful, but it was not possible to combine them. So, they recommended using the same method across populations to define the risk status of the list of populations. Hence, it might be prudent to compare these methodologies cautiously to arrive to certain conclusions. Hence, even in the absence of proper demographic data on breeds, microsatellite data scored on a reasonable number of markers may also serve the purpose of calculation of effective population size and thereby making conservation decisions.

\section{Risk status and Extinction Probability}

The estimates of extinction probability based on seven variables including NeLD or Nc are presented in Table 1 and Fig. 1 and 2. On the basis of $\mathrm{Ne}$ and other variables, the average estimated extinction probability over all the breeds was 0.41 with Attappady and Kutchi having highest extinction probability $(0.63)$ with high conservation value; and B. Bengal \& Sirohi (0.17), and Beetal (0.23) having lowest (Table 1). The extinction probability of half of the breeds was below the average value and only five breeds (Kutchi, Attappady, Ganjam, Marwari, Zalawadi) were found to be higher than $50 \%$ while Changthangi \& KanniAdu have $50 \%$ (Fig. 2). The similar values of extinction probability were also estimated in different cattle breeds with average extinction probability of 0.48 with Sheko (0.77), Highland Zebu (0.70), and Kapsiki (0.67) having the highest and Nguni (0.20), Afrikaner (0.30), and Mashona (0.32) having the lowest (Reist-Marti et al., 2003). They also estimated half of the extinction probabilities in the range of 0.40 and 0.50 , and one-third higher than 50\%. However, Gizaw et al. (2008) reported highest extinction probability of 0.90 in one sheep breed but for the rest breeds, it ranged from 0.10 to 0.50 . Pinent Tamina, (2009) reported extinction probability of chicken breeds in range of 0.76 and 0.15 .

Based on Nc and other variables, the extinction probability was found to be highest in Attappady (0.70) followed by Gohilwadi, Kutchi and Konkan kanyal (0.63) and Zalawadi (0.57) goats while lowest in Black Bengal \& Sirohi (0.10). The extinction probability for rest of the goat breeds was less than or equal to 0.50 (Fig. 1).

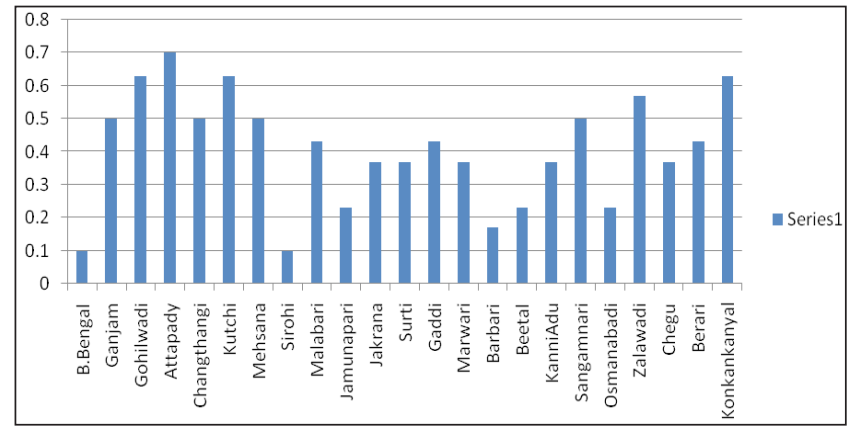

Fig. 1: Breed wise extinction probability (in \%) based on livestock breed-wise survey data

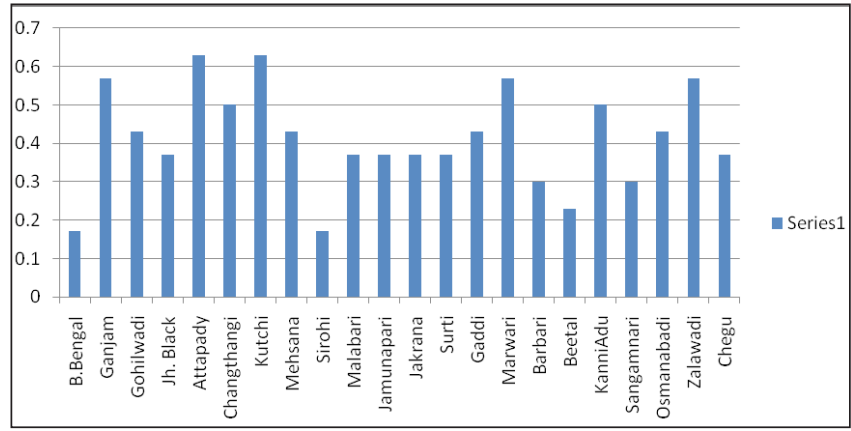

Fig. 2: Breed wise extinction probability (in \%) based on microsatellite data 
Table 1: Extinction probability and conservation value Indian goat breeds based on breed survey and STR data

\begin{tabular}{|c|c|c|c|c|c|c|}
\hline \multirow[b]{2}{*}{ Breeds } & \multicolumn{2}{|c|}{ Effective pop. size } & \multicolumn{2}{|c|}{ Extinction Probability } & \multicolumn{2}{|c|}{ Conservation Value } \\
\hline & $\begin{array}{l}\text { Based on breed } \\
\text { survey (L) }\end{array}$ & $\begin{array}{l}\text { Based on STR } \\
\text { (LDNe) }\end{array}$ & $\begin{array}{l}\text { Based on breed } \\
\text { survey (L) }\end{array}$ & $\begin{array}{l}\text { Based on STR } \\
\text { (LDNe) }\end{array}$ & $\begin{array}{l}\text { Based on breed } \\
\text { survey (L) }\end{array}$ & $\begin{array}{l}\text { Based on STR } \\
\text { (LDNe) }\end{array}$ \\
\hline B.Bengal & 84.91 & 155.1 & 0.10 & 0.17 & -10.01 & -8.17 \\
\hline Ganjam & 1.65 & 17.5 & 0.50 & 0.57 & 3.03 & 6.40 \\
\hline Gohilwadi & 0.40 & 233.7 & 0.63 & 0.43 & 7.60 & -1.19 \\
\hline Jh. Black & - & 228.5 & - & 0.37 & - & -3.72 \\
\hline Attapady & 0.04 & 75.3 & 0.70 & 0.63 & 9.48 & 6.86 \\
\hline Changthangi & 1.26 & 82.8 & 0.50 & 0.50 & 2.71 & 2.69 \\
\hline Kutchi & 1.03 & 187.5 & 0.63 & 0.63 & 6.75 & 6.86 \\
\hline Mehsana & 1.90 & 178.6 & 0.50 & 0.43 & 2.71 & -0.51 \\
\hline Sirohi & 3.76 & 132.2 & 0.10 & 0.17 & -10.01 & -8.17 \\
\hline Malabari & 1.34 & 152.8 & 0.43 & 0.37 & 1.04 & -2.15 \\
\hline Jamunapari & 6.85 & 68.3 & 0.23 & 0.37 & -5.76 & -0.80 \\
\hline Jakrana & 1.57 & 81.3 & 0.37 & 0.37 & -1.01 & -0.97 \\
\hline Surti & 1.20 & 79.6 & 0.37 & 0.37 & -1.30 & -1.30 \\
\hline Gaddi & 1.60 & 72 & 0.43 & 0.43 & 1.33 & 1.23 \\
\hline Marwari & 13.52 & 53.8 & 0.37 & 0.57 & -2.33 & 5.90 \\
\hline Barbari & 9.64 & 72.6 & 0.17 & 0.30 & -7.43 & -2.43 \\
\hline Beetal & 1.46 & 62.6 & 0.23 & 0.23 & -4.97 & -4.96 \\
\hline KanniAdu & 3.23 & 80.4 & 0.37 & 0.50 & -2.33 & 2.69 \\
\hline Sangamnari & 0.33 & 410 & 0.50 & 0.30 & 3.27 & -5.68 \\
\hline Osmanabadi & 5.75 & 58.1 & 0.23 & 0.43 & -6.29 & 1.91 \\
\hline Zalawadi & 1.14 & 100.2 & 0.57 & 0.57 & 5.08 & 5.23 \\
\hline Chegu & 0.14 & 47.9 & 0.37 & 0.37 & -0.40 & 0.27 \\
\hline Berari & 0.37 & - & 0.43 & - & 1.27 & - \\
\hline Konkankanyal & 0.10 & - & 0.63 & - & 7.60 & - \\
\hline Average & 6.23 & 119.58 & 0.41 & 0.41 & - & - \\
\hline
\end{tabular}

Both the microsatellite and demographic data revealed that Attappady and Kutchi were at highest risk of extinction probability followed by Zalawadi; and more than half of the Indian goat breeds were having less than $50 \%$ extinction probability. Thus, the order of ranking of different goat breeds either on the basis of NeLD or Nc remained almost same but differences thereof may be due to differences in blood sampling process.

\section{Conservation potential and Ranking of the breeds}

The conservation potential estimates and ranking of Indian goat breeds were presented in table 1. Based on Nc inclusive value, Attappady was at top priority followed by Gohilwadi, Konkan kanyal and Kutchi whereas based on Ne inclusive value, Attappady and Kutchi were again at top priority followed by Ganjam, Marwari, Zalawadi. Thus, Attappady and Kutchi should be given top priority for conservation based on both demographic and microsatellite data. The conservation priority of these goats might have resulted due to comparative /synergistic effect of lower effective population size, restricted distribution, increased inbreeding, lower adaptability and uniqueness.

\section{CONCLUSION}

The effective population size, extinction probability and conservation potential of 24 Indian goat breeds were assessed based on microsatellite and demographic data along with non-genetic factors such as distribution, adaptation and uniqueness of the breed. The extinction probability of most of the Indian goat breeds was $\leq 50 \%$. The study revealed that Attappady and Kutchi breeds should be considered on top priority for their conservation. The analysis of microsatellite and demographic data also revealed that microsatellites effectively predicted the effective population size and hence, the priority for conservation of breed(s). 


\section{REFERENCES}

Anonymous, breed wise information published by Indian $J$. Anim. Sci., pp. 77-83.

Bennewitz, J., Eding H., Ruane, J. and Simianer, H. 2007. Strategies for moving from conservation to utilization. In: K. Oldenbroek, ed. Utilization and conservation of farm animal genetic resources. 131-146. Wageningen, the Netherlands, Wageningen Academic Publishers.

Boettcher, P., Tixier-Boichard, M., Toro, M.A., Simianer, H., Eding, H., Gandini, G., Joost, S., Garcia, D., Colli, L., Ajmone-Marsan, P. and Globaldiv Consortium, 2010. Objectives, criteria and methods for using molecular genetic data in priority setting for conservation of animal genetic resources. Anim. Genet., 41: 64-77.

Carson, A., Elliott, Groom. J., Winter. A. and Bowles, D. 2009. Geographical isolation of native sheep breeds in the U.K evidence of endemism as a risk factor to genetic resources. Livest. Sci., 123(2-3): 288-299.

Cervantes, I., Pastor, J. M., Gutierrez, J.P., Goyache, F. and Molina, A. 2011. Computing effective population size from molecular data: The case of three rare Spanish ruminant populations. Livest. Sci., 138: 202-206.

Cuc, N.T.K., Weigend, S., Tieu, H.V. and Simianer, H. 2011. Conservation priorities and optimum allocation of conservation funds for Vietnamese local chicken breeds. $J$. Anim. Breed. Genet., 128: 284-294.

DADF, 2014, $19^{\text {th }}$ Livestock Census 2012. All India Report published by Department of Animal Husbandry, Dairying and Fisheries, Ministry of Agriculture, Government of India, New Delhi.

DADF, 2015. Estimated Livestock Population Breed-wise based on Breed Survey, 2013. Published by Department of Animal Husbandry, Dairying and Fisheries, Ministry of Agriculture, Government of India, New Delhi.

FAO, 2000. World watch list for domestic animal diversity, $3^{\text {rd }}$ ed., Rome, 2000, http://www.fao.org/dad-is/.

FAO, 2013. In vivo conservation of animal genetic resources. FAO, Animal Production and Health Guidelines. No. 14. Rome.

Falconer, D.S. and Mackay, T.F.C. 1996. Introduction to Quantitative Genetics. Addison-Wesley.

Gandini, G., Ollivier, L., Danell, B., Distl, O., Georgoudis, A., Groeneveld, E., Martyniuk, E., Van Arendonk, J.A.M. and Wolliams, J.A. 2004. Criteria to assess the degree of endangerment of livestock breeds in Europe. Livest. Prod. Sci., 91: 173-182.
Gizaw, S., Komen, H., Windig, J.J., Hanotte, O. and Van Arendonk, J.A.M. 2008. Conservation priorities for Ethiopian sheep breeds combining threat status breed merits and contributions to genetic diversity. Genet. Sel. Evol., 40: 433-447.

Hill, W.G. 1981. Estimation of effective population size from data on linkage disequilibrium. Genet. Res., 38: 209-216.

Leroy, G., Verrier, E., Meriaux, J.C. and Rognon, X. 2009. Genetic diversity of dog breeds: between-breed diversity, breed assignation and conservation approaches. Anim. Genet., 40(3): 333-343

Meuwissen, T.H.E. 2009. Towards consensus on how to measure neutral genetic diversity? J. Anim. Breed. Genet., 126: $333-$ 334.

Monomorph breed wise no. 11, 14, 29, 42, 57, 58, 60, 64, 67, 75,76 published by National Bureau of Animal Genetics Resources, Karnal-132001.

Network project reports on Animal genetic resource published by National Bureau of Animal Genetics Resources, Karnal-132001.

NATP project reports on Animal Genetic Resource published by ICAR, New Delhi.

Pinent, Tamina. 2009. Concept for planning conservation schemes for farm animal genetic diversity focused on German chicken breeds. Thesis submitted to Gottingen Centre for Biodiversity and Ecology.

Ruane, J. 1999. A critical review of the value of genetic distances in conservation of animal genetic resources. J. Anim. Breed Genet., 116: 317-323.

Reist-Marti, S.B., Simianer, H., Gibson, J., Hanotte, O. and Rege, J.E.O. 2003. Weitzman's approach and conservation of breed diversity: an application to African Cattle breeds. Conserv. Biol., 17(5): 1299-1311.

Waples, R.S. 2006. A bias correction for estimates of effective population size based on linkage disequilibrium at unlinked gene loci. Conserv. Genet., 7: 167-184.

Waples, R.S. and Do, C. 2008. LdNe: a program for estimating effective population size from data on linkage disequilibrium. Mol. Ecol. Resour., 8: 753-756.

Wright, S. 1931. Evolution in Mendelian populations. Genet., 16: $97-159$.

Zander, K.K., Drucker, A.G., Holm-Müller, K. and Simianer, H. 2009. Choosing the "cargo" for Noah's Ark -applying the Metrick-Weitzman theorem to Borana cattle. Ecol. Econ., 68: 2051-2057. 